\title{
Forensic psychiatry in Africa: prospects and challenges
}

\author{
AO Ogunlesi', A Ogunwale', P De Wet ${ }^{2}$, L Roos², S Kaliski ${ }^{3}$ \\ ${ }^{1}$ Forensic Unit, Neuropsychiatric Hospital, Aro, Abeokuta, Nigeria \\ 2Forensic Psychiatry, Department of Psychiatry, University of Pretoria, Pretoria, South Africa \\ ${ }^{3}$ Forensic Mental Health Service, Department of Psychiatry and Mental Health, University of Cape Town, Cape Town, South Africa
}

Forensic Psychiatry has a history that dates back almost two thousand years, and has evolved into a recognised discipline with a robust background of scientific enquiry, mostly because mental health care has always had an important interface with the law. ${ }^{1}$ Nevertheless, even in the developed world there are differences between countries with respect to the extent forensic mental health services have developed. This has been exacerbated by the differences in legal systems, resources and priorities in each country. Consequently comparisons and cooperation between forensic psychiatrists internationally has been difficult. ${ }^{2-4}$ In Africa, which is the second largest and most populous continent and containing an immense diversity of languages, religious traditions, ethnic groups and sociopolitical systems forensic psychiatry has largely remained underdeveloped within the context of a pervasive neglect in the provision of mental health services. ${ }^{5}$ The situation is compounded by the dearth of information about forensic services on the continent. As described by an eminent African psychiatrist, "the practice of forensic psychiatry in Africa is shrouded in both mystery and confusion". ${ }^{6}$ In addition to the lack of appropriate facilities, most countries in Africa have, on average, one psychiatrist per one million inhabitants. Moreover many psychiatrists have migrated to developed countries, leaving a small number of mental health professionals burdened with large numbers of patients. ${ }^{6}$

In most countries there are few coordinated initiatives to involve all stakeholders, such as the police, departments of justice, prisons and hospitals, in the development of forensic mental health services.

\section{West Africa}

In West Africa, forensic psychiatric services may be traced back to the colonial societies of the 1880s and the first half of the 1900s. It is important to note that the earliest vestiges of these services may have been the lunacy asylum order, Cap 79 of the former Gold Coast (Ghana) that was enacted in 1888

\section{Correspondence}

Dr AO Ogunles

email: Ogunlesi1952@yahoo.com and contained provisions for confining mental patients to institutional care, and which virtually amounted to imprisonment. ${ }^{7}$ Similarly in Nigeria, with the passing of the Lunacy ordinance of 1916 and the Federal Law in 1948, the establishment of the "asylums", which served as quasi-mental health hospitals/prisons, confirmed the status of those set up in Calabar (1903), Yaba (1907) and Lantoro (1944). Although these asylums initially only provided custodial care (while waiting for the requisite legislation to define their functions) they did ultimately develop into proper psychiatric hospitals. Generally the prisons have also had to provide alternative rudimentary forensic psychiatric services in some countries in West Africa, but, as in the hospitals, they have had critical shortages of trained personnel and medications. Throughout this region mental health legislation has also not been updated. Many countries, such as Ghana (1972), Nigeria (1958) Senegal (1975), Sierra Leone and the Gambia (1924) are still being regulated by legislation enacted decades ago. ${ }^{8}$ Training posts in forensic psychiatry remain a major limitation to the evolution of the subspecialty in West Africa. Currently, there is no formal specialty training in forensic psychiatry within the sub-region. Despite this, there is a growing reliance by the courts for forensic assessments and testimony in the region.

\section{North Africa}

In many respects the situation in North Africa is similar to that in West Africa. In Morocco and other countries most psychiatric evaluations of mentally ill offenders are conducted by general psychiatrists, many of whom are in government service.

Some parts of North Africa have institutions dedicated for the rehabilitation of mentally ill offenders, for example, in Egypt, the Abassia Hospital in Cairo and the El-Khanka Hospital in Kalyobia. Previously, only the Berrechid hospital and the Tit Mellil were selected for a similar purpose in Morocco but at present, all psychiatric institutions in the country may admit convicted persons with mental illness. Similarly in Tunisia, the Manouba, and in Algeria the Frantz Fanon Hospitals are designated forensic hospitals. ${ }^{9}$

Currently, there are no certified training programmes in forensic psychiatry within North Africa. However, according to 
Hamaoui et $\mathrm{al}^{9}$, there are now special courses being held for trainee-psychiatrists in forensic psychiatry in Egypt and these should soon be synthesized into a certified training programme.

Mental health legislation is in place in several countries in the North African sub-region. Egypt was the first country in Africa, Asia and the World Health Organization Eastern Mediterranean Region (WHO-EMRO) to have a mental health act in 1944 in spite of earlier feeble attempts in Ghana and Nigeria to enact mental health legislation in the form of ordinances in 1888 and 1916 respectively. The Egyptian 1944 Act was recently updated in April 2009, thus making Egypt the African country with the most up to date mental health legislation. In addition, the Egyptian parliament had also passed a law on substance abuse/addiction in 1985 which provides for the involuntary admission of repeated drug offenders in hospitals rather than for their diversion into the criminal justice system. In Algeria, the Law 85-05 of December, 1985 enacted for the promotion and protection of health, provides for procedures for admission of mentally ill patients and the protection of their rights. ${ }^{9}$ Tunisia also enacted Mental health legislation 1992, which was reviewed in 2004.10

\section{East and South Africa}

Many countries, such as Namibia (1973), Zimbabwe (1996) and Kenya (1989) have recently enacted mental health legislation, which probably require review.

Political changes in South Africa in the past 20 years, with the enactment of the Constitution of the Republic of South Africa, No. 108 of 1996 and the process of democratization have led to the scrapping of discriminatory legislation. ${ }^{11}$ Amendments to the South African Criminal Procedure Act and new mental health legislation, the Mental Health Care Act, No 17 of 2002 (which replaced the previous Mental Health Act of 1973) have aligned the country to current global trends, such as the shift from hospital care to community care, the integration of general health care and protection of the mentally ill user's human rights.

According to the South African Society of Psychiatrists (SASOP) database of 2009 there are 693 practicing psychiatrists in the country, of whom 343 work full-time in public service. ${ }^{12}$ The accuracy of these numbers has not been verified. Notwithstanding the actual number of practising psychiatrists in South Africa, very few are actively involved in forensic psychiatry and according to a national survey in 2008 , only 40 psychiatrists indicated a willingness to evaluate and report on accused referred from court. ${ }^{13}$

Nevertheless forensic psychiatry has been formally practiced in about 7 specially designated hospitals throughout South Africa for almost the past 100 years. Most of the assessments and treatment are now conducted by psychiatrists who are dedicated to the forensic mental health system. A burgeoning role for forensic practice in civil litigation has lead to many psychiatrists in private practice becoming involved in such matters, mostly with no peer review or official regulation. The College of Psychiatrists has recently introduced an examination for the diploma in forensic psychiatry, and subsequently the Health Professions Council of SA has accepted, by proclamation in the Government Gazette, that forensic psychiatry will be recognized formally as a sub-specialty in South Africa. Currently there are at least 10 psychiatrists whose practice is dedicated to forensic psychiatry. Some of the academic departments of psychiatry have introduced postgraduate programmes, and texts are being published to standardize the overall practice of forensic mental health. ${ }^{14,15}$

\section{Research}

Research in forensic psychiatry within Africa has included studies conducted in hospitals ${ }^{16,17}$ prisons ${ }^{18}$ and among court cohorts ${ }^{19,20}$ as well as retrospective analysis of expert evaluations of mentally ill offenders ${ }^{9}$ with a limited number of these employing standardized assessment instruments. Case reports on infanticide ${ }^{21}$, matricide ${ }^{22}$, and other forms of abnormal homicide have similarly contributed to the modest array of research efforts in forensic psychiatry within the continent. There is however a paucity of studies on suicide in this setting possibly because of methodological issues, stigma-related concerns and under-reporting to law enforcement agents on account of the criminality attached to suicide in several African countries. ${ }^{23,24}$

\section{Cultural issues}

In 2004, Layde ${ }^{25}$ having noted that cross-cultural issues have largely been neglected in forensic practice, emphasized that practitioners should attend more to language needs, cultural patterns and beliefs of different African cultures. There have been attempts to provide some guidelines for practitioners ${ }^{26,27}$, which really ought to be examined and researched in more detail. Perhaps a health care partnership between traditional healers and biomedical personal, for example under the auspices of Traditional Health Practitioners Act, No 35 of 2004 in South Africa, could address some of these issues.

\section{Recommendations}

Variations in the legislative frameworks of several countries make international collaboration for forensic psychiatry training difficult in Africa. However, it should be practicable to develop additional national residency training programmes which could involve affiliation with recognized institutions in countries where forensic psychiatry training is more organized. Such linkages provide opportunities for psychiatrists, who may wish to specialize in forensic psychiatry, to have specially tailored attachment programmes in the established institutions, gain the prerequisite skills in setting up services for mentally ill offenders and return to their native countries to train others as well as adapt these skills to the existing legal frameworks. To drive advocacy in favour of organized forensic psychiatry training and practice in Africa, there is no time more suitable than the present to set up an "African Association of Forensic Psychiatrists". This Association may be developed under the aegis of the African Association of Psychiatrists and Allied Professionals (AAPAP).

Further, inter sectoral initiatives, involving representatives from the Departments of Justice, Police and Correctional Services should be established in all countries. Specific to South Africa and Africa as a whole, cultural, religious and linguistic issues and difficulties also affect the application of psychiatry in the judicial systems and the differing roles of health workers who have to practice within the many systems. 


\section{References}

1. Gutheil TG. The history of forensic psychiatry. Journal of American Academy of Child and Adolescent Psychiatry 2005; 33(2):259-262.

2. Srinivasaraghavan J. International work in forensic psychiatry. Current Opinion in Psychiatry 2007; 20(2):51 6-520.

3. Arboleda-Florez J. Forensic psychiatry: Contemporary scope, challenges and controversies. World Psychiatry 2006; 5(2):87-91.

4. Velinov VT, Marinov PM. Forensic psychiatric practice: Worlwide similarities and differences. World Psychiatry 2006; 14(2):98-99.

5. Morakinyo VO. The law and psychiatry in Africa. African Journal of Psychiatry 1977; 3:91-98.

6. Njenga F. Forensic psychiatry:The African experience. World Psychiatry 2006; 14(2):97.

7. Kumi NB. Ghana's Mental Health Law. Human Rights meeting at European Parliament . 2006

8. World Health Organization. Mental Health Atlas 2005. 2005. World Health Organisation.

9. Hamaoui YE, Moussaoui D, Okasha T. Forensic psychiatry in North Africa. Current Opinion in Psychiatry 2009; 22:507-510.

10. Ministry of Health Tunisia and WHO. A report of the assessment of teh mental health system in Tunisia using the World Health Organization - Assessment Instrument for Mental Health Systems (WHO-AIMS). 2008. Tunis, Tunisia.

11. Mihalik J. Legal aspects of forensic psychiatry in South Africa. Med Law 1992; 11:239-248.

12. Questionnaire in mental health and substance abuse. Johannesburg: Intersectoral conference, 2008.

13. Allan A, Louw DA, Verschoor T. Law and psychology in South Africa: development and recommendations (3). Med Law 1995; 14:685692.

14. Kaliski SZ. Introduction. In: Kaliski SZ, editor. Psycholegal Assessment in South Africa. Cape Town: Oxford University Press, 2006: 1-7
15. Zabow T. Forensic psychiatric evaluation: Clinical, ethical and procedural issues in South Africa. Med Law 1998; 17:69-75.

16. Ogunlesi $O A$. Offenders admitted to the Neuropsychiatric Hospital, Aro. Abeokuta. A ten year review. West African Journal of Medicine 1988; 7:210-215.

17. Kaliski SZ. A comparison of risk factors for habitual violence in pretrial subjects. Acta Psychiatr Scand Suppl 2002;(412):58-61.

18. Fatoye FO, Fatoye GK, Oyebanji AO, Ogunro AS. Psychological characteristics as correlates of emotioanl burden in incarcerated offenders in Nigeria. East Afr Med J 2006; 83(10):545-552.

19. Odejide AO. Criminal justice and psychiatry: A study of the pattern of criminality in Ibadan Division. African Journal of Medical Sciences 1980; 8:41-44.

20. Kaliski SZ, Borcherds M, Williams F. Defendants are clueless- the 30 day psychiatric observation. South African Medical Journal 1997; 87(10):1351-1355.

21. Sulyman D, Yussuf AD, Ajiboye PO, Adefalu MO. Infanticide in an outpatient psychiatric of a university teaching hospital in Nigeria. A case report. Nigerian Journal of Psychiatry 2010; 8(2):15-17.

22. Ogunwale A, Abayomi O. Schizophrenia and matricide in the 21st century: Two case reports, in press 2011.

23. Asuni T. Suicide in Western Nigeria. British Medical Journal 1962; 2(5312):1091-1097.

24. Akhiwu WO, Nwosu SO, Aligbe JU. Homicide and suicide in BeninCity, Nigeria. Anil Aggrawal's Internet Journal of Forensic Medicine and Toxicology 1[2]. 2000.

25. Layde JB. Cross-cultural issues in forensic psychiatry. Academic Psychiatry 2004; 28(1):34-39.

26. Fernando S, Ndegwa D, Wilson M. Forensic Psychiatry, race and culture. London: Routledge, 1998.

27. Swartz L. Transcultural psychiatry in South Africa. Transcultural Psychiatric Research Review 1986; 23:273-292.
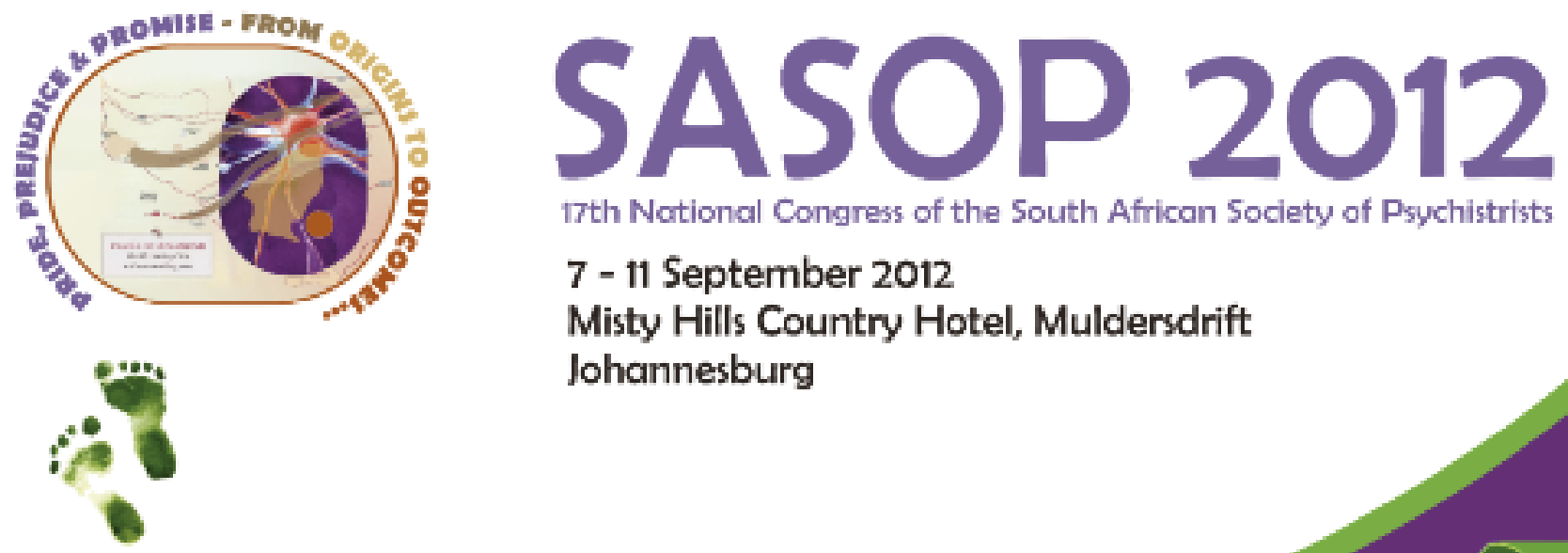

17th National Congress of the South African Society of Psychistrists

\section{7 - 11 September 2012 Misty Hills Country Hotel, Muldersdrift Johannesburg}

For further information please contact the congress organisers on: Londocor Event Management Tel: $\mathbf{4 2 7 1 1 7 6 8 4 3 5 5}$ E-mail: sonja/Olondocor.co.za / ywonne(Olondocor.co.za 